Neuroradiology 8, $131-139$ (1974)

(C) by Springer-Verlag 1974

\title{
Cerebral Angiography in Meningeal Sarcomatosis and Carcinomatosis*
}

\author{
R. E. Latchaw,** T.O. Gabrielsen and J.F. Seeger \\ Department of Radiology, University of Michigan Medical Center, Ann Arbor, Michigan, USA
}

Received: July 10, 1974

\begin{abstract}
Summary. The angiographic findings in a case of metastatic meningeal carcinomatosis and a case of primary meningeal sarcomatosis are presented. The presence of focal arterial narrowing at the base of the brain and/or over the cerebral convexities, with or without a communicating hydrocephalus, may be the important clues to a diagnosis of diffuse meningeal involvement by tumor. In a patient who presents with bizarre and poorly localizing signs and symptoms, when the cerebrospinal fluid analysis does not fully support a diagnosis of meningitis or subarachnoid hemorrhage, and when there is nothing in the history to suggest drug abuse or a systemic collagen disease, the angiographic findings may point to an unexpected diffuse meningeal tumor.
\end{abstract}

Angiographie cerebrale des sarcomatose et carcinomatose meningees

Résumé. Les auteurs rapportent les données angiographiques dans lun cas de carcinomatose méningée métastatique et dans un cas de sarcomatose méningée primitive. La présence de sténoses artérielles localisées à la base du cerveau et/ou au niveau des convexités cérébrales avec ou sans hydrocéphalie communicante peuvent représenter des signes importants en faveur d'un envahissement tumoral méningé diffus. Chez un malade présentant une symptomatologie atypique et mal localisée,
Iorsque l'examen du liquide céphalo-rachidien ne parle pas franchement en faveur d'une méningite ou d'une hémorragie méningée et lorsque l'anamnèse n'évoque aucune intoxication exogène ni collagénose, les données angiographiques peuvent faire découvrir une tumeur méningée diffuse.

Cerebrale Angiographie bei meningealer Sarkomatose und Karzinomatose

Zusammenfassung. In der vorliegenden Arbeit werden die angiographischen. Befunde eines Falles einer metastatischen meningealen Karzinomatose und eines Falles einer primären meningealen Sarkomatose geschildert. Dabei läßt sich besonders die umschriebene arterielle Gefäßeinengung an der Basis des Gehirns und/oder über den Konvexitäten beobachten. Dieser Befund kann mit einem Hydrocephalus communicans kombiniert sein. Wenn bei einem Patienten merkwürdige und schlecht lokalisierbare neurologische Symptome vorliegen, wenn durch die Liquoruntersuchung die Diagnose einer Meningitis oder einer Subarachnoidalblutung nicht gesichert werden kann und wenn bei dem Patienten auch kein Drogen-Abusus besteht, ist bei den beschriebenen angiographischen Veränderungen an eine diffuse meningeale Tumorabsiedlung zu denken.
Primary cerebral meningeal sarcomatosis or meningeal carcinomatosis can be extremely difficult to diagnose before autopsy. The main purpose of this paper is to report some angiographic observations which may, in the context of the clinical findings, provide clues to the correct diagnosis. A brief review of some pertinent pathological and clinical features along with differential diagnostic possibilities will be presented.

\section{Material}

During the last few years we have performed cerebral angiography on four patients who, at autopsy, had either primary sarcomatosis or metastatic carcinomatosis involving the cerebral meninges. One patient with each type of lesion will be presented in detail.

* Presented at the Eleventh Annual Meeting of the American Society of Neuroradiology, Boston, Massachusetts, April 26-28, 1973.

* This study was supported in part by a Special Fellowship in Neuroradiology (R.E.L.), 5 F11 NS0247602, from the National Institute of Neurological Diseases and Stroke.

\section{Report of Cases}

Case 1. This 50 year old female was admitted to another hospital in May 1970 with a two month history of frontal headache, blurred vision, unsteady gait, nausea and vomiting. Bilateral optic atrophy, nystagmus, diplopia on right lateral gaze, a partial right homonymous hemianopia, and ataxia of the right arm and leg were said to have been. present at that time. A lumbar puncture revealed normal pressure. Spinal fluid examination showed normal protein and glucose, a nonreactive VDRL, no red blood cells, 25 leukocytes per $\mathrm{mm}^{3}$, (15 polymorphonucleocytes and 10 monocytes), and negative culture. Angiography demonstrated hydrocephalus and an incidental arteriovenous malformation of the scalp without an intracranial component.

The patient became progressively more confused and lethargic during the succeeding few weeks. A repeat lumbar puncture revealed a pressure of $360 \mathrm{~mm}$ CSF. A ventriculoatrial shunt was inserted on May 29, 1970 with improvement in the patient's level of consciousness and a decrease in the headache.

Confusion, lethargy, nausea, and vomiting became prominent again during July, and the patient was admitted to the University of Michigan Medical Center on July 28, 1970. She was afebrile, disorientated, and had nuchal rigidity, bilateral optic atrophy, generalized muscular weakness and atrophy, and diffusely hypoactive reflexes. The rest of the physical findings were unchanged from the previous hospitalization.

Multiple lumbar punctures were performed during her hospital course, with the CSF protein constantly rising to 

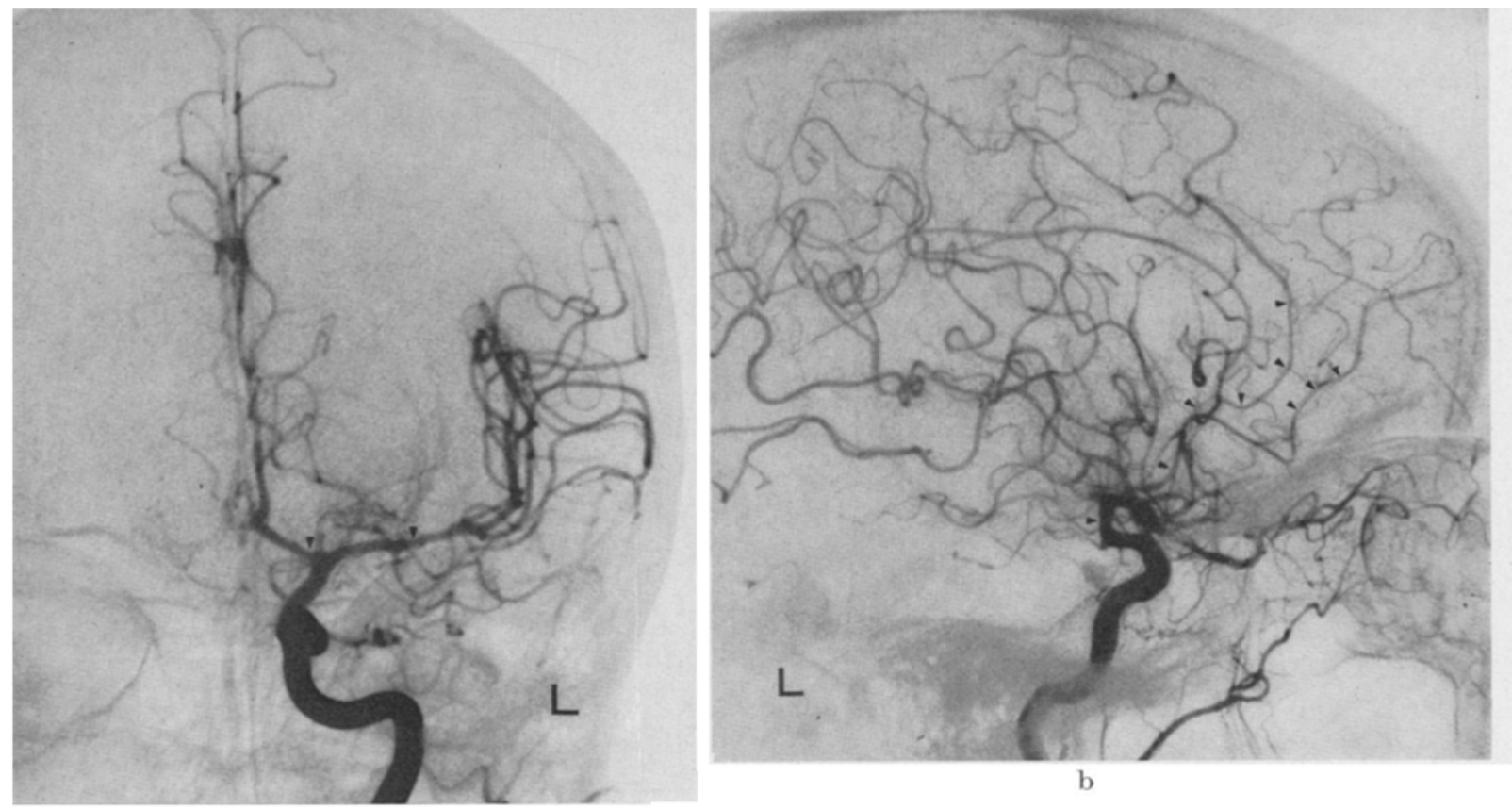

b

a

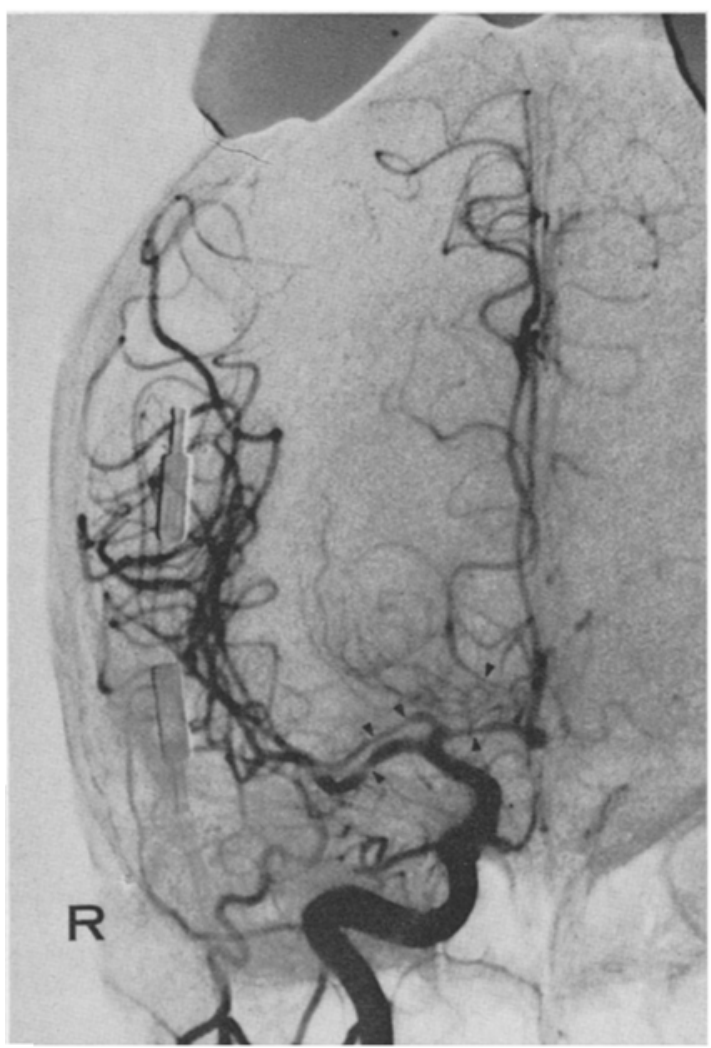

c

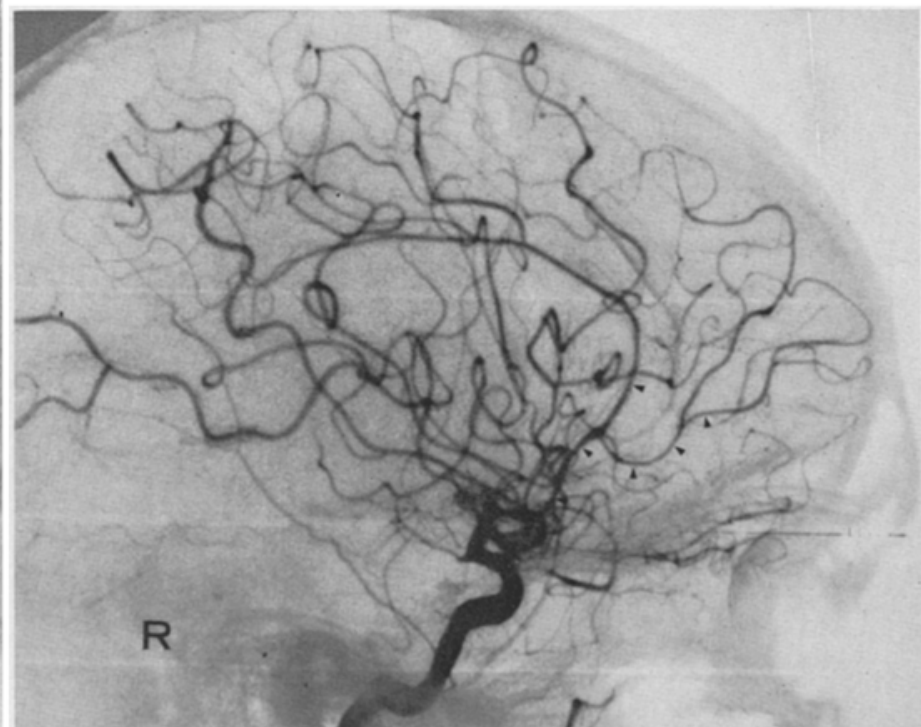

d

Fig. 1. Case 1. (a and b). Left carotid angiography. The AP view (a) shows focal areas of narrowing of the distal internal carotid artery and the proximal anterior and middle cerebral arteries (arrowheads). The lateral view (b) also shows narrowing of the distal internal carotid artery (lowest arrowhead) and segmental narrowing of the anterior cerebral artery and its branches within the frontal portion of the interhemispheric fissure (arrowheads). (c and d). Right carotid angiography. The anteroposterjor (c) and lateral (d) views show changes very similar to those on the left (arrowheads). The areas of segmental narrowing of the anterior cerebral artery branches in $b$ and $d$ can best be appreciated by comparison with the caliber of more distal parts of the same branches 
a peak of $750 \mathrm{mg} \%$. The glucose fell to a low of $20 \mathrm{mg} \%$. A few monocytes were present but multiple cultures for bacteria, fungi, and TB, and multiple CSF cytological examinations were consistently negative. A ${ }^{99 \mathrm{~m} T e}$ brain. scan on July 28 was negative.

Complete cerebral angiography on July 29 failed to demonstrate an intracranial mass lesion. Circulation time was slightly increased. There was moderate dilatation of the lateral ventricles. The left carotid angiogram showed multiple areas of vaseular irregularity and narrowing involving not only the arteries at the base of the brain, but also more peripheral branches, particularly within the
At autopsy, gross examination of the brain revealed thick, cloudy leptomeninges around the brain stem, at the base of the cerebrum, and within the sylvian and interhemispheric fissures (Fig. 3a). Histologically, there was diffuse infiltration of the leptomeninges by sarcoma, with perivascular extension (Fig. $3 \mathrm{~b}$ ). Microscopic examination of the cerebral vessels themselves showed extensive spread of neoplasm within the adventitia (Figs. $3 \mathrm{c}$ and $\mathrm{d}$ ). A thorough search was made throughout the rest of the brain, especially the cerebellum and the spinal theca, and throughout the rest of the body, but no tumor was found outside the cerebral leptomeninges and contiguous few
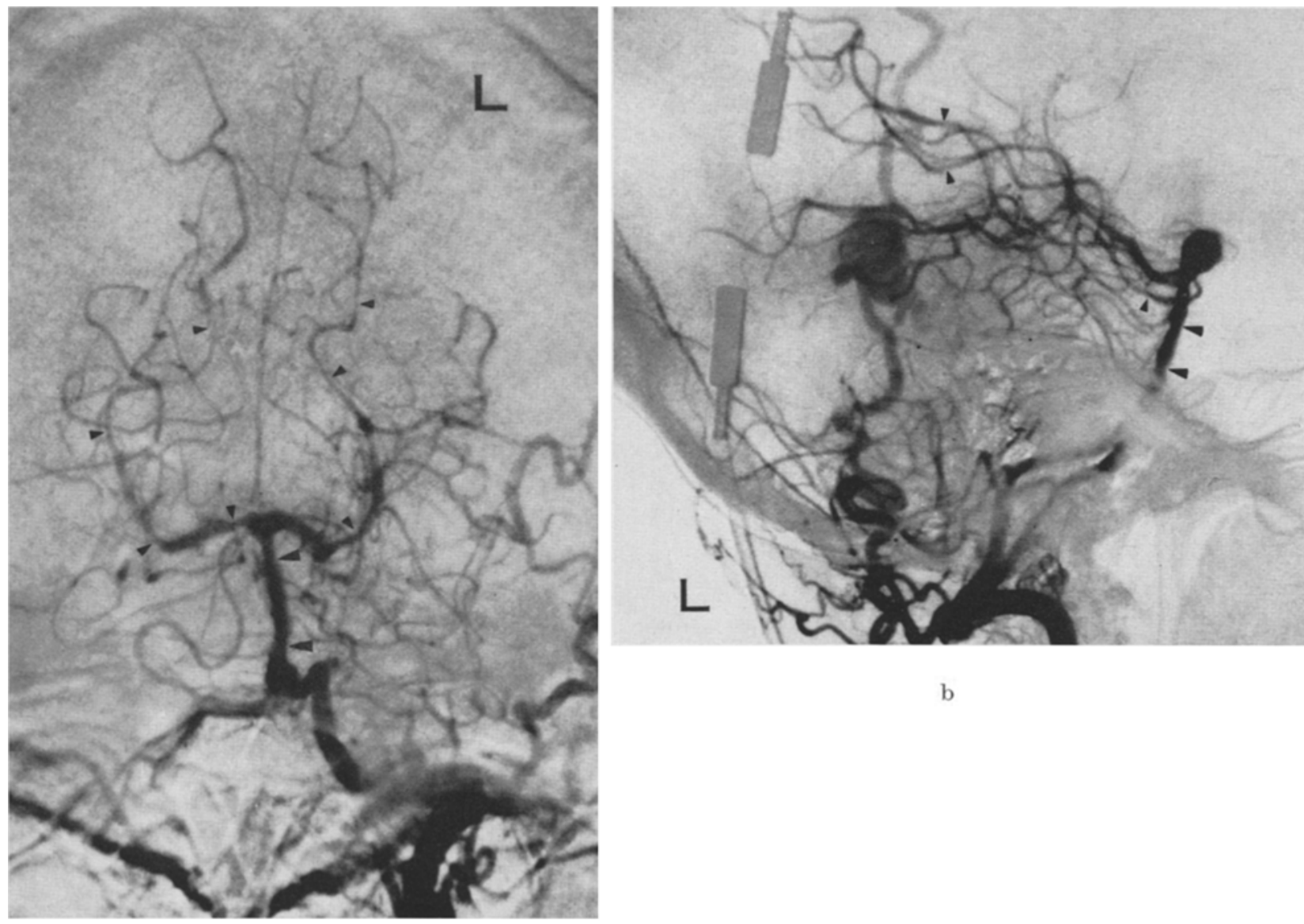

b

Fig. 2. Case 1. Left vertebral angiography. Anteroposterior (a) and lateral (b) views show foci of irregular narrowing of the basilar artery (large arrowheads) and of the posterior cerebral arteries, both proximally and peripherally (small arrowheads)

interhemispheric fissure in the frontal region (Figs. $1 \mathrm{a}$ and b). The right carotid angiogram showed similar findings (Figs. $1 \mathrm{c}$ and d). The left vertebral angiogram demonstrated marked irregularity of the basilar artery, and irregular narrowing of both posterior cerebral arteries, both proximally and further peripherally (Figs. 2a and b).

There was never any clinical indication of a subarachnoid hemorrhage, nor were there consistent clinical findings to suggest an infectious process. The possibility of meningeal carcinomatosis was suggested because of the angiographic features in correlation with the clinical findings. However, the patient was treated for a possible fungal or tuberculous meningitis but he deteriorated progressively and expired one month later. millimeters of cerebral cortex. This was considered to be a primary leptomeningeal sarcomatosis.

Case 2. This 60 year old female had a long history of a mass in the right breast. On February 26, 1971 she gave a three to four week history of headaches and blurred vision. Physical examination revealed a large, ulcerating mass in the right breast and enlarged right axillary nodes, as well as masses in the left breast and axilla. Neurological examination was normal except for the finding of bilateral papilledema. During the subsequent week the patient gradually became less alert. By March 3, 1971 she was semicomatose and had generally hypoactive reflexes and nuchal rigidity. The patient was afebrile during the entire period. 


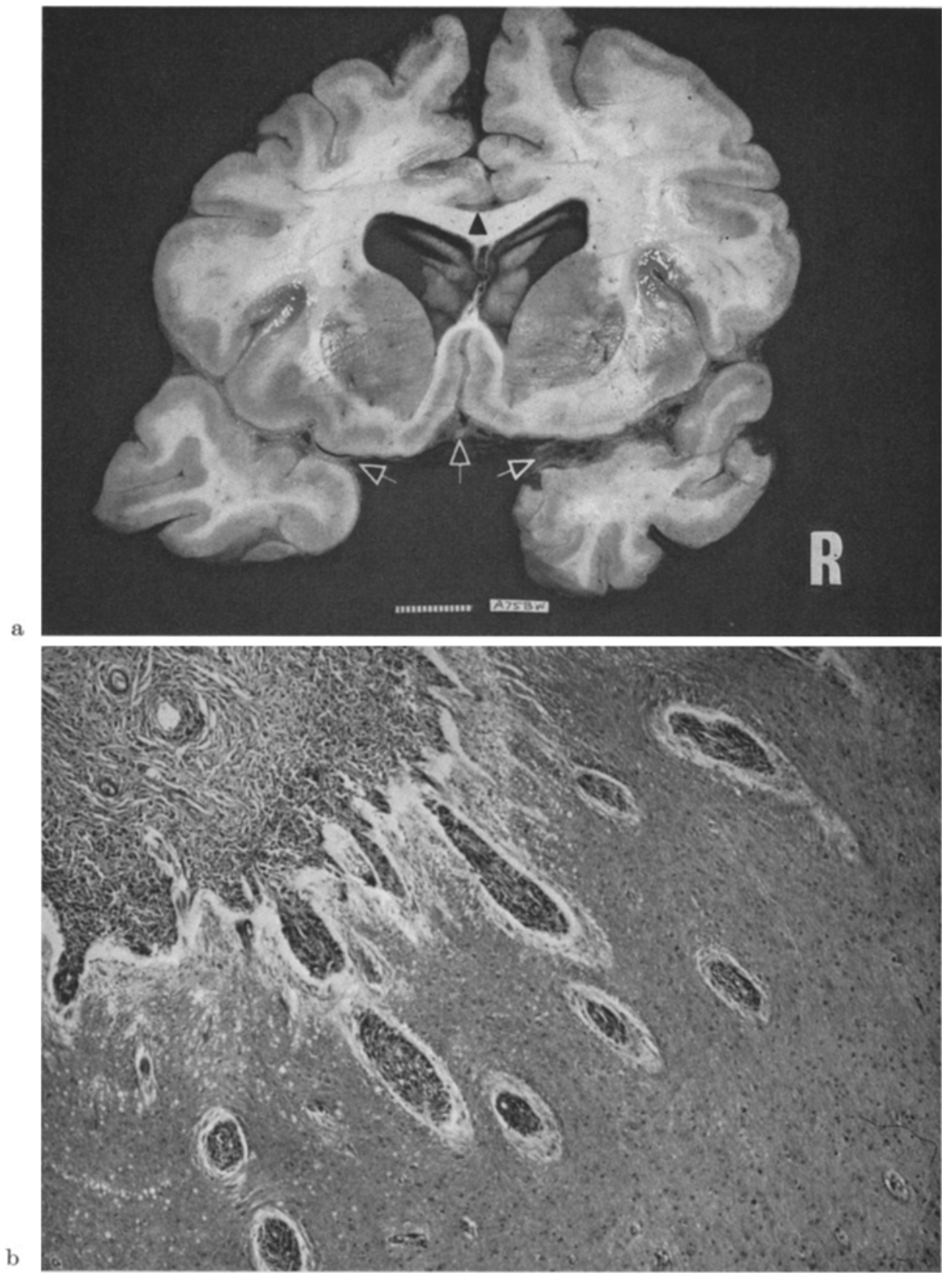

Fig. 3. Case 1. Coronal section of the brain (a) demonstrates meningeal infiltration at the base extending into the sylvian fissures (open arrows) and within the pericallosal cistern (arrowhead). Microscopic section of cortex adjacent to the sylvian fissure (b) shows perivascular infiltration of sarcoma. Microscopic view of a coronal section through the mesencephalon (c) demonstrates infiltration by sarcoma of the leptomeninges surrounding the brainstem, particularly well seen in the interpeduncular fossa (closed arrow), and involvement of multiple vessels including the basilar artery (open arrow). A high power view of the wall of the basilar artery (d) shows extensive tumor infiltration of the adventitia

A skeletal survey on March 1 demonstrated destruction of the left pedicle of the third lumbar vertebra. A ${ }^{99 m}$ Tc brain scan on March 2 was normal. Complete cerebral angiography two days later showed no evidence of a localized intracranial expansion. There was moderate hydrocephalus which appeared to be on a "pressure" basis. Left carotid angiography revealed slight narrowing of the supraclinoid portion of the internal carotid artery, and irregular narrowing of the middle and anterior cere- bral arteries (Figs. $4 \mathrm{a}$ and b). Similar changes on the right were seen on right carotid angiography. Vertebral angiography was normal.

Because there was no definite clinical evidence of meningitis and no source of subarachnoid hemorrhage was found at angiography, the possibility of meningeal carcinomatosis was raised in this patient with a large ulcerated breast mass.

When a ventriculoatrial shunt was inserted on March 


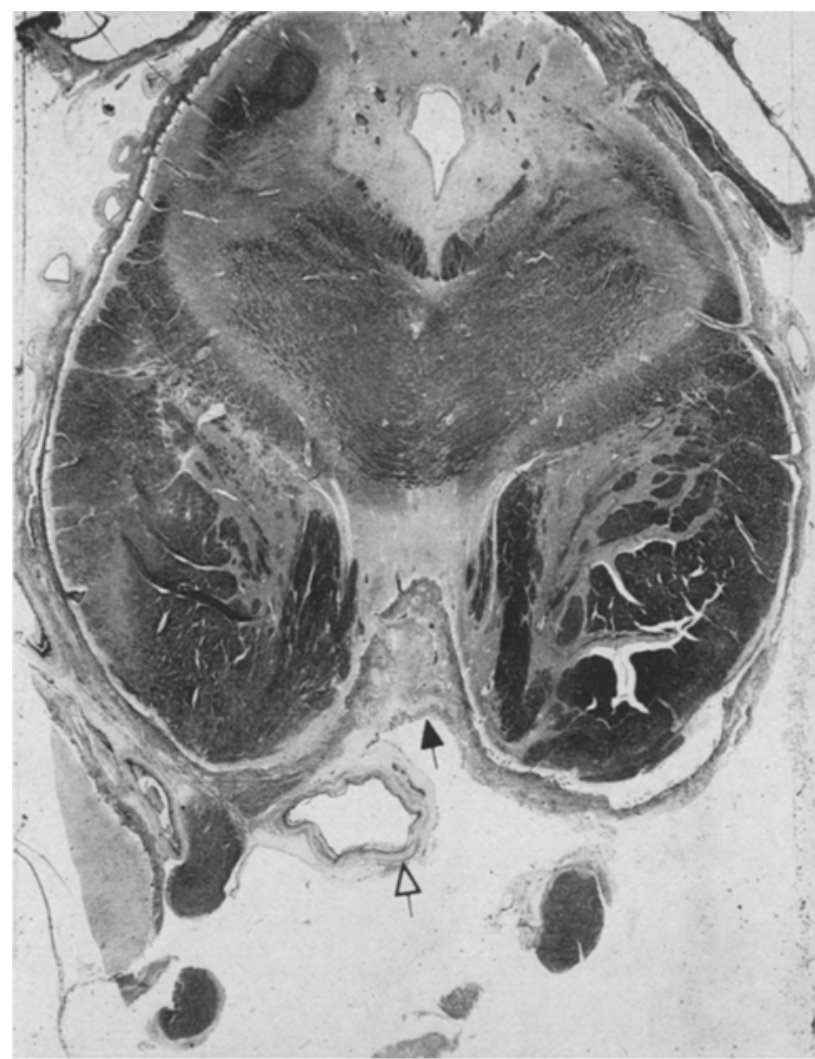

Fig. 3e

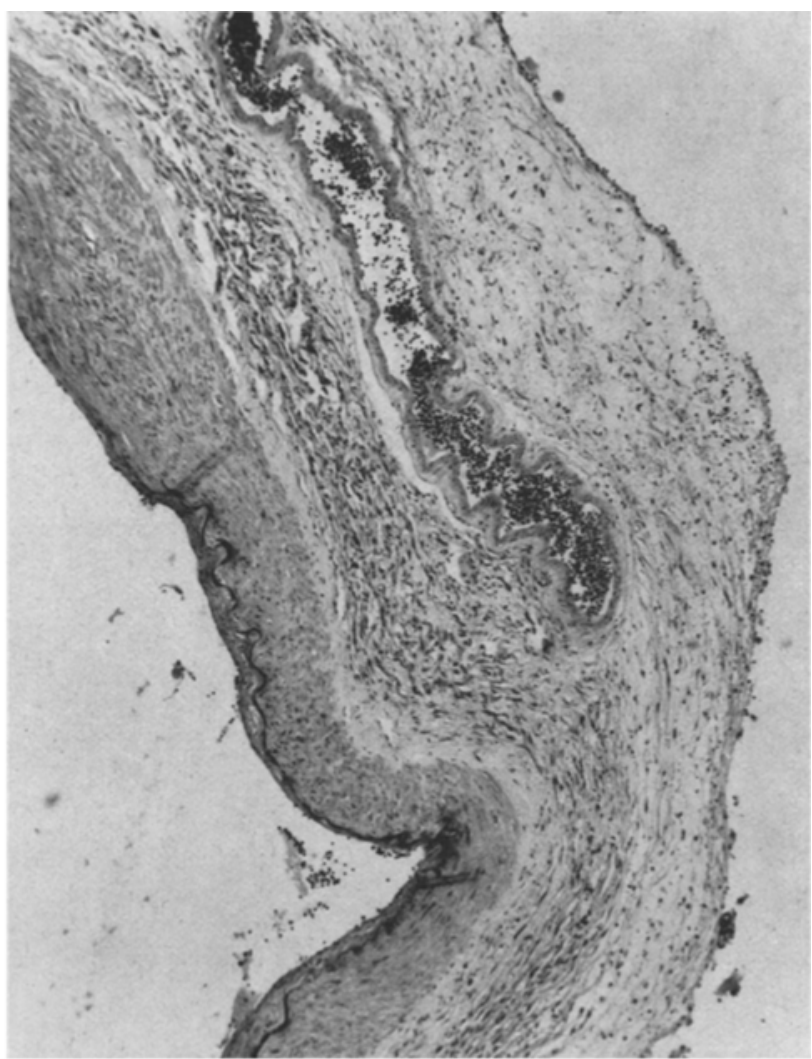

Fig. 3d
5 , the intraventricular pressure was $350 \mathrm{~mm}$ of ventricular fluid. No abnormal cells were found in the ventricular fluid and cultures were negative. The patient improved markedly and continued to do well for another year. She was treated with several chemotherapeutic agents administered orally and parenterally.

She was rehospitalized on February 9, 1972 for progressive confusion and meningismus. The opening pressure on lumbar puncture was $50 \mathrm{~mm}$ CSF. Fluid analysis showed a protein of $384 \mathrm{mg} \%$, glucose of $70 \mathrm{mg} \%$ and adenocarcinoma cells.

The patient expired on February 24, 1972. At autopsy, gross examination of the brain revealed hydrocephalus and a widespread pink-to-tan thickening of the leptomeninges, particularly at the base of the brain. Microscopic examination demonstrated metastatic adenocarcinoma infiltrating the leptomeninges, perivascular spaces, and superficial cerebral cortex. Of particular interest, in view of the angiographic findings, was gross and microscopic evidence of direct involvement of the walls of both large and small cerebral arteries (Figs. 5 and 6). There was no localized intracranial metastatic neoplastic mass except for a small nodule in the hypothalamus. The cellular characteristics of the infiltrating meningeal tumor were identical to the primary breast neoplasm.

\section{Discussion}

\section{Pathology}

Diffuse involvement of the meninges by neoplastic growth without localized tumefaction is rare $[1,5,7$, 13]. In most instances, diffuse tumors of the meninges are the result of spread from gliomas, particularly medulloblastomas, although most intracranial tumors can produce widespread meningeal involvement $[1,5$, 13].

Primary diffuse meningeal sarcomatosis rarely occurs and can be difficult to diagnose even at autopsy, both with respect to gross detection and the exclusion of extrameningeal origin $\left[\begin{array}{lll}1 & 13,22\end{array}\right]$. The extensive neoplastic tissue may be so thin that it cannot be recognized grossly, or it may be several millimeters thick, especially at the base of the brain $[1,13]$. Greyish-white flecks are sometimes seen within the diffusely thickened arachnoid which may lead to a mistaken diagnosis of tuberculosis [1]. Hydrocephalus may result from obstruction to the flow of cerebrospinal fluid [13]. Microscopically, there is frequently extensive spread of tumor along perivascular spaces deep into the cerebral sulci and occasionally some infiltration into the superficial layers of the cerebral cortex $[1,13,22]$.

Metastases to brain parenchyma from extracranial sources are frequent, but diffuse involvement of the meninges, without gross nodules in the parenchyma and/or meninges, is relatively rare $[5,7,21]$. Although a variety of primary neoplasms, including melanoma, may be responsible, most cases are adenocarcinomas [7]. The primary lesions originate typically in the 


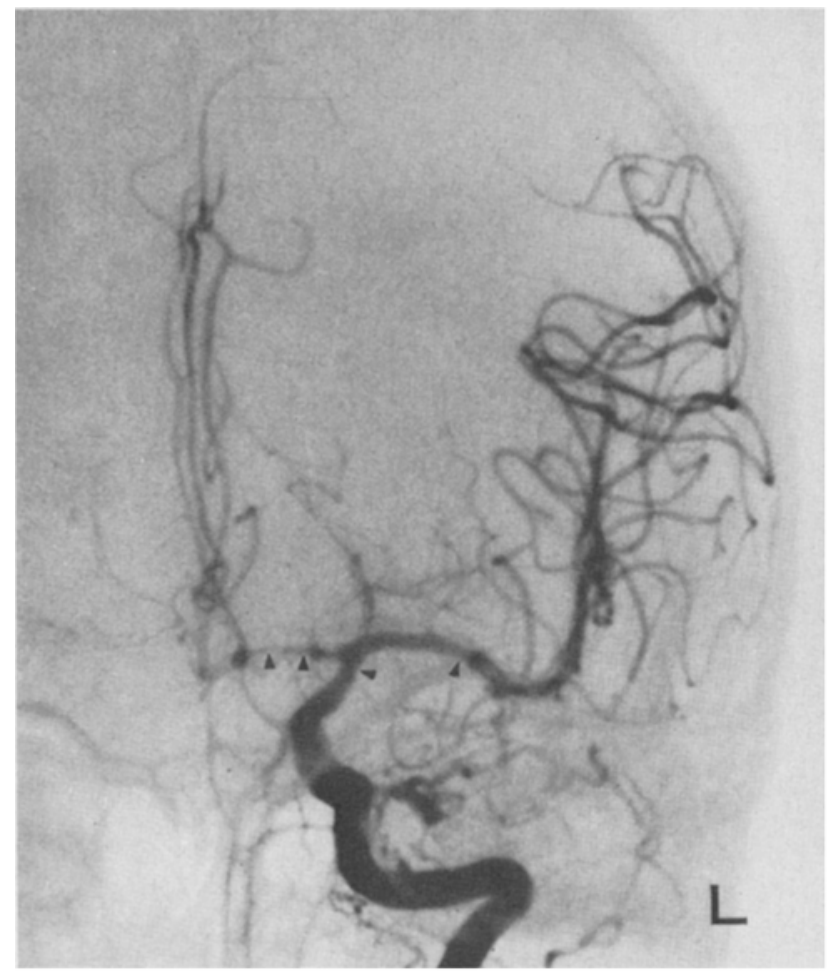

Fig. 4a

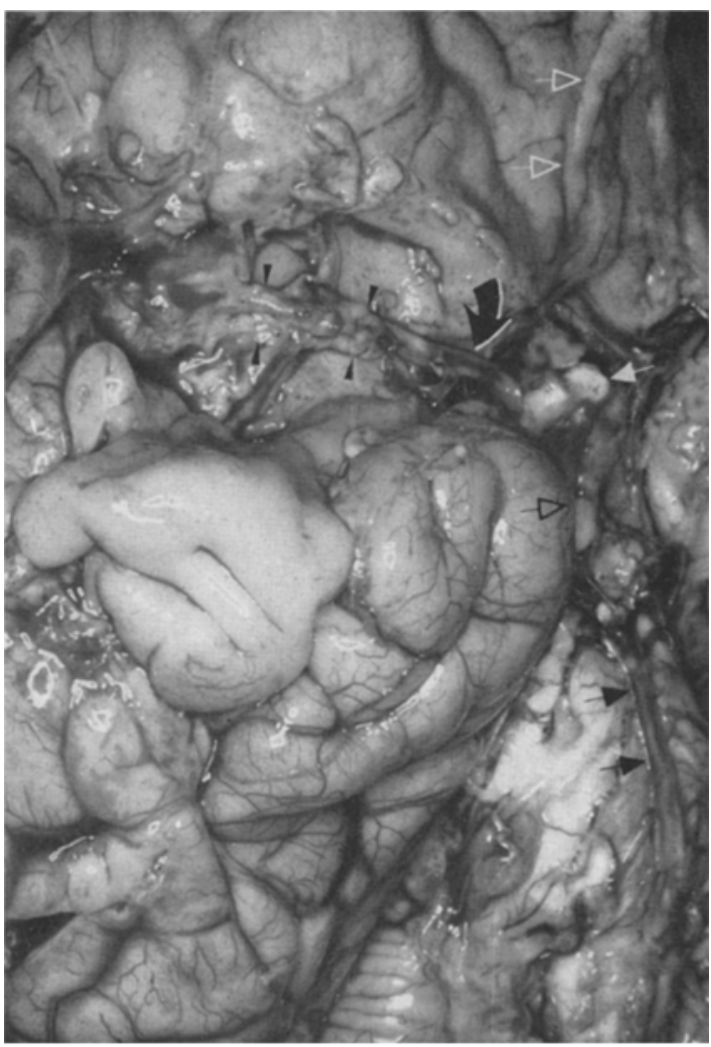

Fig. 5

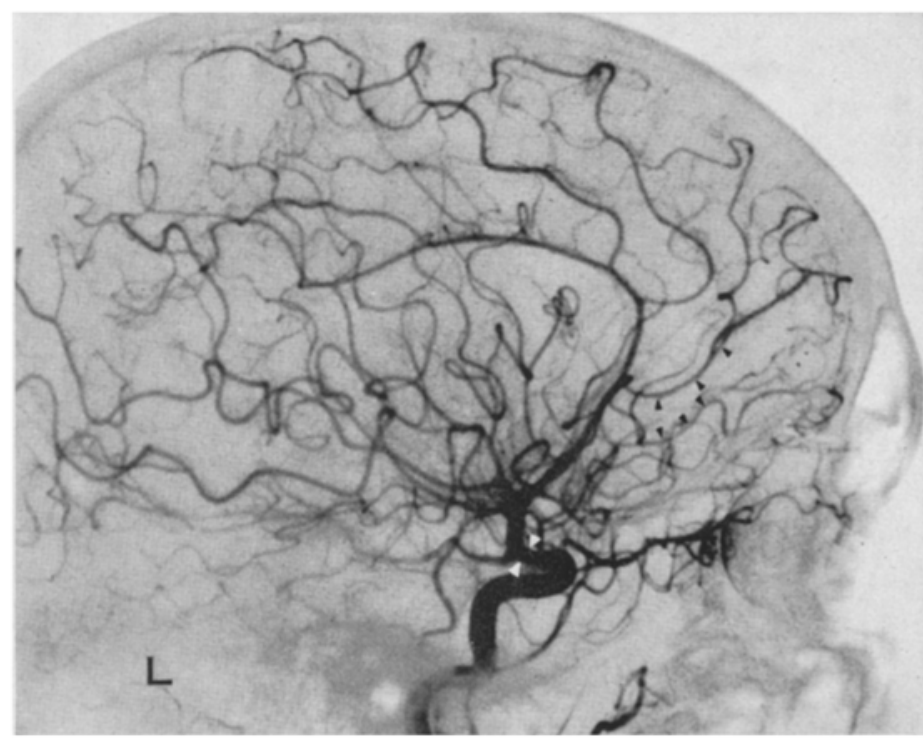

Fig. 4b

Fig. 4. Case 2. Left carotid angiography. The AP view (a) demonstrates irregular narrowing of the proximal portions of the anterior and middle cerebral arteries (arrowheads). The lateral view (b) shows narrowing of the internal carotid artery just proximal to the posterior communicating artery (white arrowheads), and slight segmental narrowing of proximal anterior cerebral artery branches compared with distal segments (black arrowheads)

Fig. 5. Case 2. View of base of the brain at autopsy. For orientation: basilar artery - closed black arrows, tip of uncus - open black arrow, optic chiasm - closed white arrow, olfactory stalk - open white arrows, proximal right middle cerebral artery - large curved arrow. The tip of the right temporal lobe has been resected to demonstrate the "encasement" of middle cerebral artery branches (arrowheads) in the proximal sylvian fissure 
gastrointestinal tract, particularly the stomach and colon, or in the breast or lung $[3,5,7,11,21]$. It is interesting to note that intracranial metastases from gastrointestinal neoplasms are infrequent, but the distribution of the metastases in such cases is often meningeal [7]. As is true of sarcomatosis, the presence of meningeal carcinomatosis may not be grossly recognized at autopsy if the layer of neoplastic cells is thin. However, the gross appearance characteristically is a hazy grey clouding of the meninges which may be confined to the base of the brain and may be mistaken for meningitis $[5,7]$. There may be hydrocephalus [3, $5,7,21]$. The microscopic pattern is similar to that seen with meningeal sarcomatosis, with frequent extensive spresd along perivascular spaces $[3,5,7,21]$ and occasional superficial invasion of cerebral cortex [21].
$7,13,21,22]$. Characteristically there is no associated fever $[3,7,11]$. Lumbar puncture usually will reveal an elevated and occasionally a markedly elevated CSF pressure $[1,3,5,7,11,13,21,22]$. Vision often is affected, and the patient fairly frequently has either papilledema or optic atrophy $[1,3,5,7,13,21,22]$.

The neoplastic cells of either meningeal sarcomatosis or carcinomatosis may infiltrate cranial and spinal nerves extensively $[1,3,5,7,11,21]$, with symptoms mimicking polyneuritis $[3,5,7]$. Consistent localizing neurological findings are unusual $[5,7]$.

Cerebrospinal fluid analysis ordinarily will show a mild pleocytosis, low sugar content, and elevated protein concentration which may reach extremely high levels $[3,5,7,21]$. Although cultures are consistently negative, the nonspecific clinical and laboratory find-

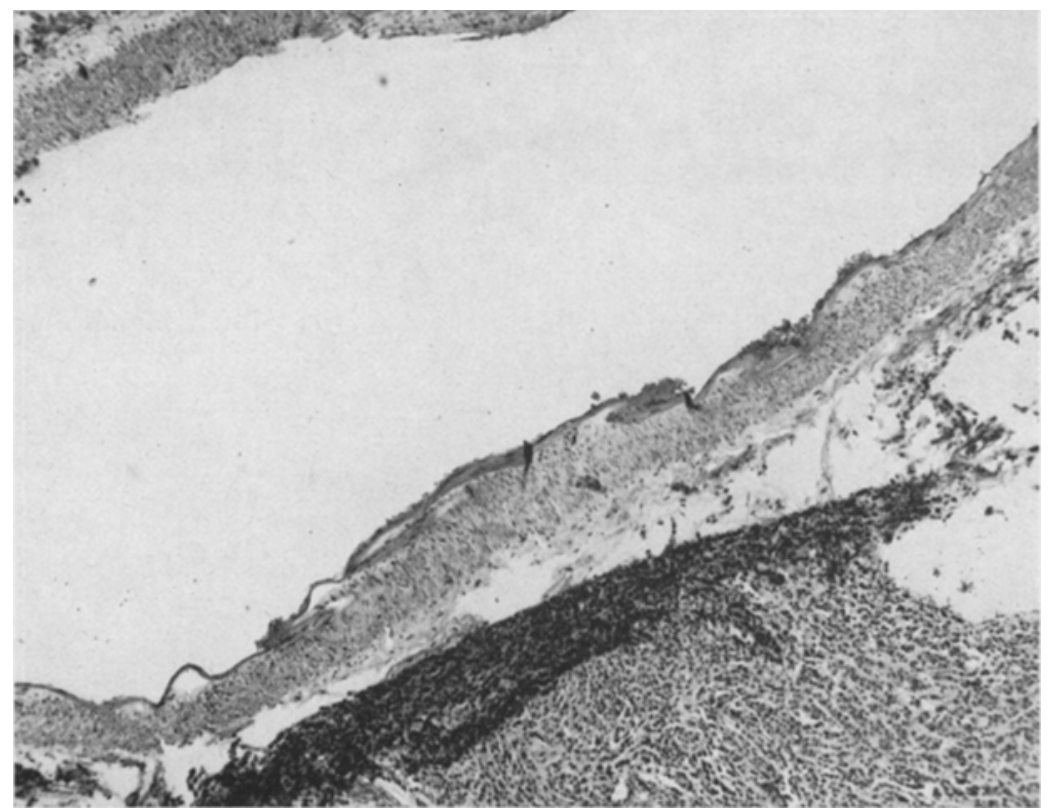

Fig. 6. Case 2. Microscopic section through the wall of the middle cerebral artery demonstrates infiltration of the adventitia by adenocarcinoma

In our two cases, tumor not only accompanied small vessels deep into sulci, but actually infiltrated the adventitia of large muscular arteries (Figs. 3, 5, and 6).

\section{Clinical Features}

It is usually very difficult to make a diagnosis of primary meningeal sarcomatosis before autopsy [13]. It may also be difficult to make an antemortem diagnosis of meningeal carcinomatosis, particularly if the patient has no evidence of an extracranial neoplasm [21]. There may be slowly progressive neurological symptoms pointing to a brain tumor or chronic meningitis, or a fairly rapid downhill course suggesting a more fulminant meningitis $[3,5,7,11,13,21,22]$.

The patients may have headache, dementia, a depressed level of consciousness, neurotic or psychotic behavior, urinary incontinence, or convulsions $[1,3,5$, ings frequently lead to empirical treatment for meningitis, particularly the tuberculous and fungal varieties, even in the absence of significant fever $[3,7,11]$. This may often be a reasonable approach because of the possible clinical similarities between tuberculous meningitis and meningeal spread of tumor and the fact that tuberculous meningitis may occur without significant fever [16].

The cytological demonstration of malignant cells in the CSF is diagnostic [5, 7]. However, the cytology may not be positive before death, or may not become positive until late in the course of the disease [21].

\section{Angiography}

Cerebral angiography was performed on four patients who at autopsy had either meningeal sarcomatosis or carcinomatosis. One patient with a final 
pathological diagnosis of a primary undifferentiated neoplasm of the cerebral meninges had no definite abnormality shown by complete cerebral angiography performed two month before death. Another patient with an autopsy diagnosis of metastatic breast carcinomatosis to the cerebral meninges showed hydrocephalus and minimal peripheral cerebral vascular irregularities at angiography ten days before death. The two cases that have been described in detail had vascular changes which, when correlated with the clinical findings, suggested the correct diagnosis.

Both cases demonstrated varying degrees of narrowing of the vessels at the base of the brain, particularly of the supraclinoid portions of the internal carotid arteries and the proximal portions of the anterior and middle cerebral arteries. Case 1 also showed irregular narrowing of the basilar artery. Focal narrowing of more peripheral vessels was also present, particularly of anterior and posterior cerebral artery branches in Case 1 (Figs. 1 and 2), and of anterior cerebral artery branches in Case 2 (Fig. 4). There was direct correspondence between the sites of vascular irregularity seen angiographically and the areas of tumor infiltration of the vessel wall demonstrated microscopically.

\section{Differential Diagnosis}

The angiographic findings described above are not specific for meningeal sarcomatosis or carcinomatosis. Subarachnoid hemorrhage from any one of a variety of causes may produce arterial narrowing ("spasm"). When due to bleeding from an aneurysm or arteriovenous malformation, there is generally no difficulty in establisbing the correct diagnosis.

Cerebral inflammatory disease, particularly meningitis, may produce arterial changes indistinguishable from those in our cases of meningeal sarcomatosis and carcinomatosis $[4,6,14,16,19,28]$. Associated angiographic findings, such as arteriovenous shunting and/or abnormal "staining", may be seen in inflammatory conditions and might aid in the differentiation. The clinical findings, including fever, and CSF abnormalities, including positive culture, are sufficiently characteristic to make differentiation possible in most cases. Tuberculous meningitis is the inflammatory condition which presumably could cause the greatest difficulty in differential diagnosis, not only because it might present with similar angiographic features (arterial narrowing most pronounced at the base of the brain) $[6,16]$ but also because of the occasional similar clinical picture, including apyrexia [16].

Atherosclerotic disease may produce vascular irregularities very similar to those seen in our cases. However, atherosclerotic narrowing is usually of an eccentric nature, with plaque formation affecting a portion of the arterial lumen rather than its entire circumference [15].

Other entities which might demonstrate similar angiographic findings include cerebral embolization, particularly with recanalization, occlusive vascular diseases in children $[8,26]$, including those associated with the neurocutaneous syndromes [9], and sicklecell anemia $[17,25]$. Drug abuse, particularly with the amphetamines, has recently been shown to produce diffuse cerebral vascular changes [23]. The focal areas of narrowing may appear quite similar to those of our cases. Microaneurysms and focal areas of dilatation, seen in some of the patients with drug abuse, were not seen in our series. Collagen diseases $[10,24,27]$, embolic cardiac myxoma [20], radiation arteritis [12] and meningovascular syphilis [17] also may produce cerebral arterial irregularities.

Lastly, arterial irregularities have been described when there is local invasion of cerebral arteries by tumor $[2,15,18]$. It has been stated that the distinguishing angiographic feature of vascular irregularity caused by tumor is that the involved vessels will be confined to the area of the tumor mass [15]. This association is no doubt most frequent when a tumor causes irregularity of the cerebral arteries and will often help in clarifying the diagnosis. However, our cases demonstrate that multiple areas of vascular abnormality may be present with a diffusely spreading tumor without evidence of tumefaction. As far as we are aware, this phenomenon has not been reported previously.

\section{References}

1. Black, B.K., Kernohan, J.W.: Primary diffuse tumors of the meninges (so-called meningeal meningiomatosis). Cancer 3, 805-819 (1950)

2. Cowen, R.L., Siqueira, E.B., George, E.: Angiographic demonstration of a glioma involving the wall of the anterior cerebral artery. Radiology $\mathbf{9 7}, 577-578$ (1970)

3. Dinsdale, H.B., Taghavy, A.: Carcinomatosis of the meninges. Canad. med. Ass. J. 90, 505-512 (1964)

4. Ferris, E.J., Rudikoff, J.C., Shapiro, J.H.: Cerebral angiography of bacterial infection. Radiology 90, $727-734(1968)$

5. Fischer-Williams, M., Bosanquet, F.D., Daniel, P.M. : Carcinomatosis of the meninges: A report of three cases. Brain 78, 42-58 (1955)

6. Greitz, T.: Angiography in tuberculous meningitis. Acta Radiol. (Diag.) 2, 369-378 (1964)

7. Hawkins, D., Brown, D.: Meningeal carcinomatosis. Canad. med. Ass. J. 88, 225-228 (1963)

8. Hilal, S.K., Solomon, G.E., Gold, A.P., Carter, S.: Primary cerebral arterial occlusive disease in children. Part I: Acute acquired hemiplegia. Radiology 99, $71-86(1971)$

9. Hilal, S.K., Solomon, G.E., Gold, A.P., Carter, S.: Primary cerebral arterial occlusive disease in children. Part II : Neurocutaneous syndromes. Radiology 99, 87-93 (1971)

10. Hinck, V.C., Carter, C.C., Rippey J.G. Giant cell (cranial) arteritis: A case with angiographic abnormalities. Amer. J. Roentgenol. 92, $769-775$ (1964)

11. Hughes, I.E., Adams, J.H., Ilbert, R.C. Invasion of leptomeninges by tumor: the differential diagnosis from tuberculous meningitis. J. Neurol. Neurosurg. Psychiat. 26, $83-89$ (1963) 
12. Kagan, A.R., Bruce, D.W., DiChiro, G.: Fatal foam cell arteritis of the brain after irradiation for Hodgkin's disease: Angiography and pathology. Stroke 2, $232-238$ (1971)

13. Kernohan, J.W., Uihlein, A.: Sarcomas of the Brain, pp. 16-18, 99-107, 161-162. Springfield: Thomas 1962

14. Leeds, N.E., Goldberg, H.I.: Angiographic manifestations in cerebral inflammatory disease. Radiology 98, 595-604 (1971)

15. Leeds, N.E., Rosenblatt, R. : Arterial wall irregularities in intracranial neoplasms: The shaggy vessel brought into focus. Radiology 103, 121-124 (1972)

16. Lehrer, H.: The angiographic triad in tuberculous meningitis: A radiographic and clinicopathologic correlation. Radiology 87, 829-835 (1966)

17. Liebeskind, A., Cohen, S., Anderson, R., Schechter, M.M., Zingesser, L.H.: Unusual segmental cerebrovascular changes. Radiology 106, 119-122 (1973)

18. Lin, J.P., Siew, F.P.: Glioblastoma multiforme presenting angiographically as intracranial atherosclerotic vascular disease. Radiology 101, 353-354 (1971)

19. Lyons, E.L., Leeds, N.E.: The angiographic demonstration of arterial vascular disease in purulent meningitis. Radiology 88, 935-938 (1967)

20. New, P.F. J., Price, D. L., Carter, B.: Cerebral angiography in cardiac myxoma: Correlation of angiographic and histopathological findings. Radiology 96 , $335-345(1970)$

21. Olson, M.E., Chernik, N.L., Posner, J.B.: Leptomeningeal metastases from systemic cancer: A report of 47 cases. Trans. Amer. neurol. Ass. 96, 291-293 (1971)

22. Onofrio, B.M., Kernohan, J.W., Uihlein, A. : Primary meningeal sarcomatosis. A review of the literature and report of 12 cases. Cancer 15, 1197-1208 (1962)

23. Rumbaugh, C.L., Bergeron, R.T., Fang, H.C.H., McCormick, R.: Cerebral angiographic changes in drug abuse patients. Radiology, 101, 335-344 (1971)

24. Sievers, K., Nissila, M., Sievers, U.M.: Cerebral vasculitis visualized by angiography in juvenile rheumatoid arthritis simulating brain tumor. Acta rheum. scand. 14, 222-232 (1968)

25. Stockman, J.A., Nigro, M.A., Mishkin, M. M., Oski, F.A.: Occlusions of large cerebral vessels in sicklecell anemia. New Engl. J. Med. 287, 846-849 (1972)

26. Taveras, J.M.: Multiple progressive intracranial arterial occlusions: A syndrome of children and young adults. Am. J. Roentgenol, 106, 235-268 (1969)

27. Trevor, R.P., Sondheimer, F.K., Fessel, W.J., Wolpert, S.M.: Angiographic demonstration of major cerebral vessel occlusion in systemic lupus erythematosis. Neuroradiol. 4, 202-207 (1972)

28. Wickbom, G.I., Davidson, A.J.: Angiographic findings in intracranial actionomycosis. Radiology $\mathbf{8 8}$, $536-537(1967)$

T. O. Gabrielsen, M.D.

Department of Radiology

University of Michigan

Medical Center

Ann Arbor, Mich. 48103

U.S.A. 